\title{
CUTANEOUS METASTASIS OF BREAST CARCINOMA: A RARE PRESENTATION
}

\author{
Luckymoni Duara ${ }^{1}$, Aparna Dutta ${ }^{2}$
}

${ }^{1}$ Assistant Professor, Department of Pathology, Assam Medical College, Dibrugarh.

${ }^{2}$ Assistant Professor, Department of Pathology, Assam Medical College, Dibrugarh.

\section{ABSTRACT}

Breast carcinoma metastasis is the most common carcinoma encountered in clinical practice. Cutaneous metastasis is one of the most distressing presentations of metastatic breast cancer. This may occur as the initial manifestation of undetected internal malignancy or the first sign of dissemination or even as the first sign of recurrence. Here, we report a case of skin metastasis, i.e. carcinoma en cuirasse in a 70 years old female who presented with painless, nodular, itchy skin lesion on right anterior chest wall extending to the right arm. On further examination, a hard lump of size $3 \times 2 \times 1 \mathrm{~cm}$ was palpated in the right breast. FNAC of the breast and skin lesion were performed. Cytodiagnosis was given as infiltrating duct carcinoma of breast with metastatic carcinoma involving right anterior chest wall and right arm. So, skin lesion is an alarming sign and should be further evaluated.

\section{KEYWORDS}

Cutaneous Metastasis, Carcinoma of Breast, Cancer En Cuirasse.

HOW TO CITE THIS ARTICLE: Duara L, Dutta A. Cutaneous metastasis of breast carcinoma: a rare presentation. J. Evolution Med. Dent. Sci. 2016;5(15):736-738, DOI: 10.14260/jemds/2016/169

\section{INTRODUCTION}

Breast cancer is the most common cancer in women. The incidence of cutaneous metastasis in patients with breast carcinoma is $23.9 \% .^{[1]}$ Initial skin presentation varies as nodule or papule, telangiectatic, erysipeloid, en cuirasse, alopecia neoplastica, zosteriform.[1,2] Metastatic cutaneous carcinoma is also termed as Carcinoma en cuirasse.[3] Cutaneous metastasis presents most commonly a few months or years after the primary has been diagnosed. Sometimes a metastasis is diagnosed at the same time as the primary tumor or presents as the first manifestation of the disease. ${ }^{[4]}$ Carcinoma en cuirasse is rare and is described as fibrotic, hard, leathery plaque involving the thoracic wall. Usually nodular, but rarely metastases present in a zosteriform distribution.[5]

\section{CASE REPORT}

A 70 years old female presented with painless nodular itchy skin lesion on right anterior chest wall extending to right arm in 4 months' duration. On examination, elevated erythematous, indurated, non-tender plaque were found on the right anterior chest wall measuring $2 \mathrm{~cm}$ extending into the right arm over an area of size $4 \times 2 \times 1 \mathrm{~cm}$. After examination of the right breast, an immobile hard lump measuring $3 \times 2 \times 1 \mathrm{~cm}$ was palpated. Axillary lymph nodes were palpable. Left breast was normal.
Financial or Other, Competing Interest: None.

Submission 05-01-2016, Peer Review 03-02-2016,

Acceptance 08-02-2016, Published 22-02-2016.

Corresponding Author:

Dr. Aparna Dutta,

Assistant Professor

Department of Pathology,

1st Floor, Basic Science Building,

Assam Medical College \& Hospital,

Dibrugarh-786002, Assam.

E-mail: draparnakamal@gmail.com

DOI: $10.14260 / \mathrm{jemds} / 2016 / 169$

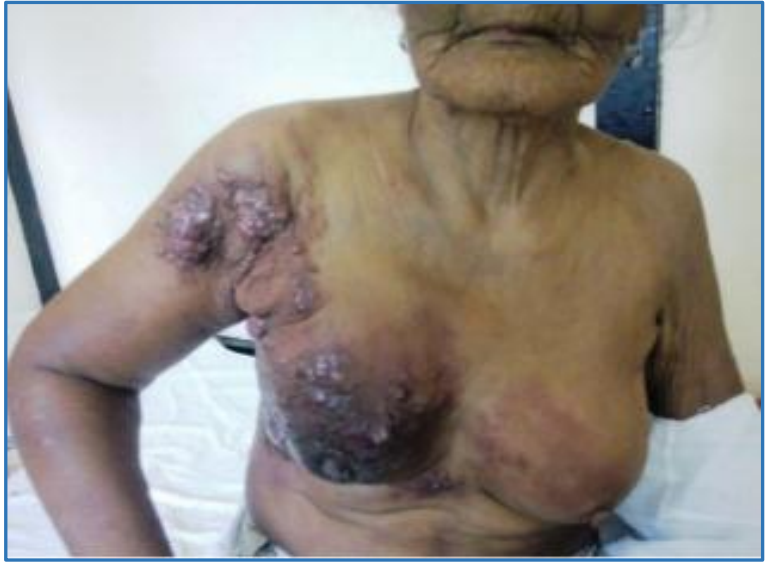

Fig. 1: Clinical photograph of papulonodular lesion over an erythematous surface on right side of anterior chest wall and right upper arm

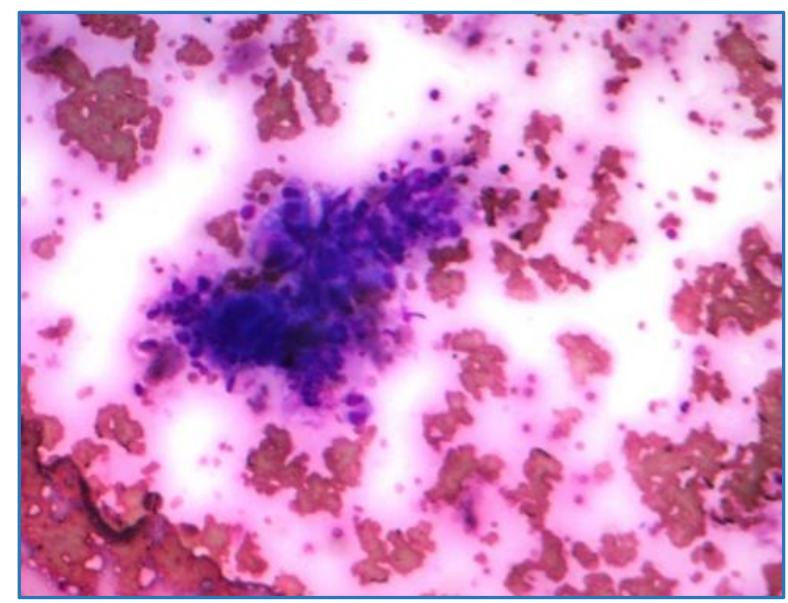

Fig. 2: Photomicrograph of FNAC of skin lesions showing sheets of malignant cells (Low Power) 


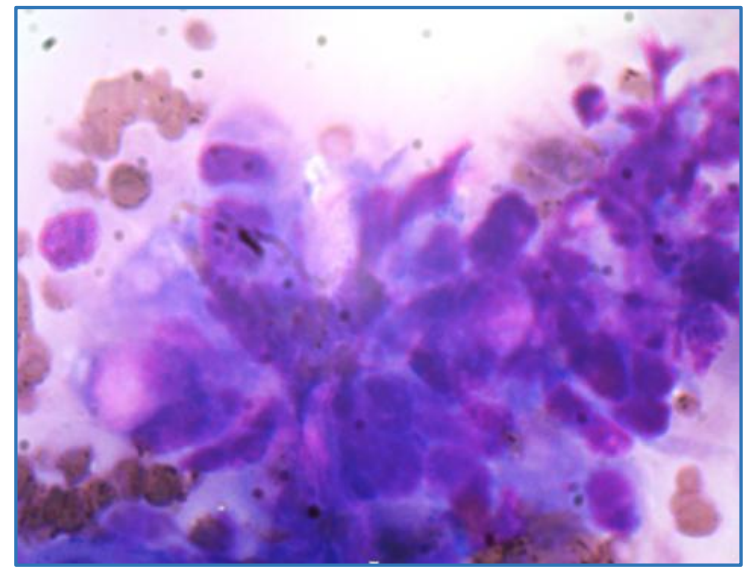

Fig. 3: Photomicrograph of FNAC of skin lesions showing sheets of malignant cells (High power)

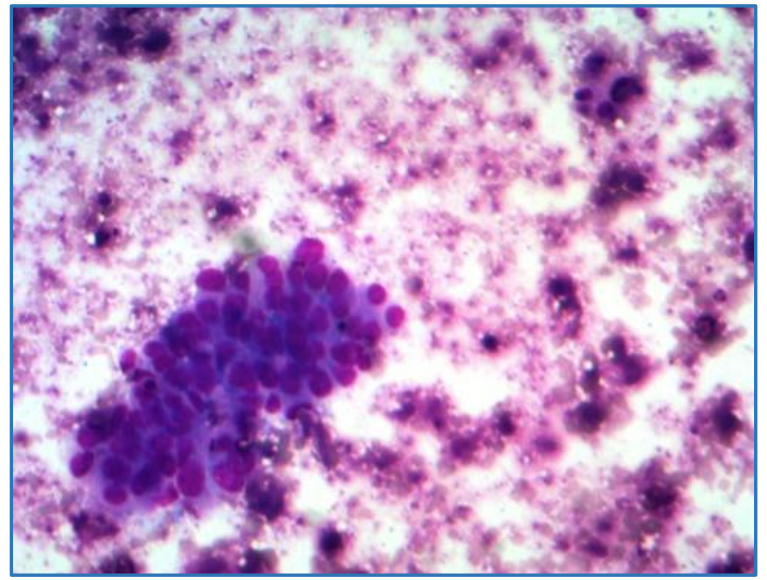

Fig. 4: Photomicrograph of FNAC of breast lump showing loose cohesive clusters of malignant cells (Low power)

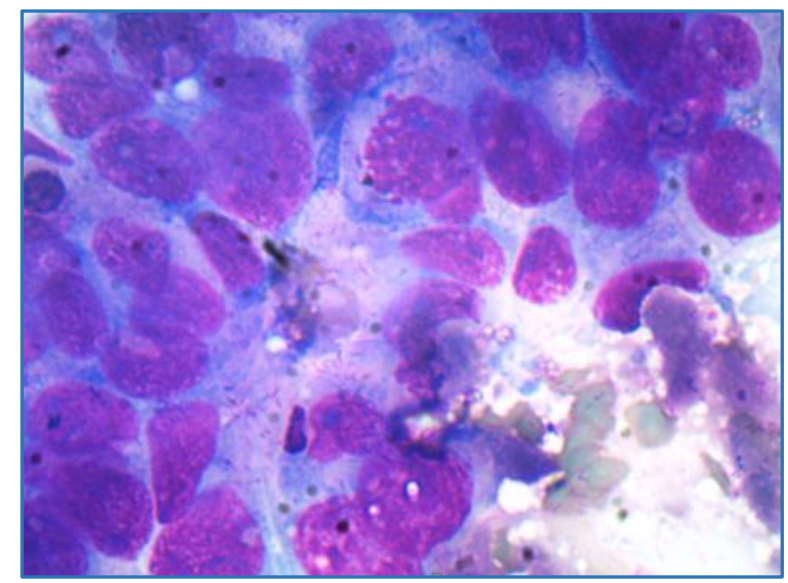

Fig. 5: Photomicrograph of FNAC of breast lump showing clusters of malignant cells, few cells are arranged in acinar pattern (High power)

The cells were loose cohesive clusters, few cells were arranged in acinar pattern. The individual cells show nuclear enlargement, pleomorphism with irregular nuclear membrane, prominent nucleoli, coarsely clumped chromatin and moderate amount of cytoplasm with tumor necrosis.

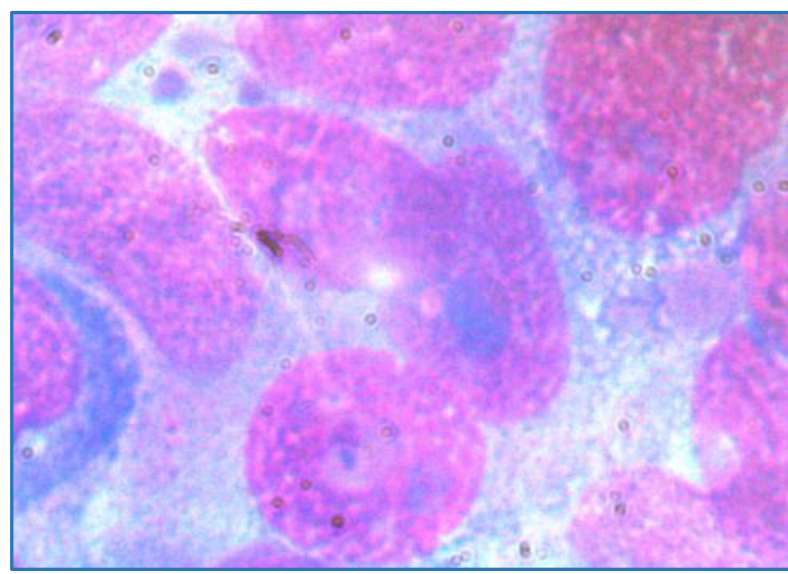

Fig. 6: Photomicrograph of FNAC of breast lump showing nuclear enlargement, prominent nucleoli and coarsely clumped chromatin (Oil immersion)

\section{CYTOLOGY FINDINGS}

Fine needle aspiration of the lump of the breast, right chest wall lesion and right arm was performed. MGG stained smears from all the above sites show similar cytological features. Smears from the breast lump revealed high cellularity.

\section{DISCUSSION}

Cutaneous metastasis are not uncommon. They are estimated to be ranging from $0.7 \%-10.4 \%$ in patients with cancer.[1]

First described by Velpeau in 1838, because of its resemblance to the metal breast plate of a cuirassier. In a breast cancer patient, other possible etiologies besides cutaneous metastasis includes cutaneous change, either acute or chronic-secondary to radiation therapy or other infectious processes such as erysipelas, cellulitis or candidiasis.[6]

En cuirasse metastatic carcinoma begin as scattered, firm lenticular papulonodules over an erythematous or smooth cutaneous surface. The nodules have no inflammatory changes. In an autopsy series of 7158 patients with visceral malignancy, $26.5 \%$ of women with breast carcinoma were found to have cutaneous metastasis.[7]

In a recent retrospective review by Mordenti et al.[3] 164 cases of skin metastases specifically form breast carcinoma were examined to determine the most common clinical and histopathological presentations. Skin papules and/or nodules were found in $80 \%$ of patients, telangiectatic carcinomas in $11 \%$, erysipeloid carcinomas in $3 \%$, 'en cuirasse' carcinomas in $3 \%$, alopecia neoplastica in $2 \%$ and a zosteriform type in $0.8 \%{ }^{[3]}$

Although, the most common carcinoma to metastasize to the skin is malignant melanoma, seconded by breast carcinoma. Breast cancer is very common in females and cutaneous metastasis of breast cancer is the commonly encountered metastasis in clinical practice. ${ }^{[3]}$

\section{CONCLUSION}

Cutaneous metastasis presents most commonly a few months or years after the primary has been diagnosed. But here we present a case where metastasis is diagnosed at the same time as the primary tumour. 


\section{BIBLIOGRAPHY}

1. De Giorgi V, Grazzini M, Alfaioli B, et al. Cutaneous manifestations of breast carcinoma. Dermatol Ther 2010;23:581-9. [PubMed]

2. Hussein MR. Skin metastasis: a pathologist's perspective. J Cutan Pathol 2010;37:e1-e20 [PubMed].

3. Mordenti C, Peris K, Concetta Fargnoli M, et al. Cutaneous metastatic breast carcinoma. [Last accessed on 2011 January 28]; Acta Dermatovenerol Alp Panonica Adriat 2000;9:4.

4. Sadhana D Mahore, Kalpana A Bothale, Anjali D Patrikar, et al. Carcinoma en cuirasse: a rare presentation of breast cancer [IAPM 2010, Page 53(2)].
5. Bassioukas K, Nakuci M, Dimou S, et al. Zosteriform cutaneous metastases from breast adenocarcinoma. J Eur Acad Dermatol Venereol 2005;19:593-6. [PubMed]

6. Guillermina Nava, Kenneth Green, James Patterson, et al. Metastatic cutaneous breast carcinoma: a case report and review of the literature. Can J Plastic surgery 2009 spring; 17(1):25-27.

7. Spencer PS, Helm TN. Skin metastases in cancer patients. Cutis 1987;39:119-21. [PubMed] 